\title{
Effects of Screencasting on the Turkish Undergraduate Students' Achievement and Knowledge Acquisitions in Spreadsheet Applications
}

\author{
Erkan Tekinarslan \\ Abant Izzet Baysal University, Bolu, Turkey \\ erkantekinarslan@gmail.com \\ Executive Summary
}

The purpose of this study is to investigate the effects of screencasts on the Turkish undergraduate students' achievement and knowledge acquisitions in spreadsheet applications. The methodology of the study is based on a pretest-posttest experimental design with a control group. A total of 66 undergraduate students in two groups ( $\mathrm{n}=33$ in experimental, and $\mathrm{n}=33$ in control) participated both in the multiple choice and practical pretests and posttests. There was no significant difference between the mean achievement scores of the experimental and control groups in the multiple choice and practical pretests. Nevertheless, there was a significant difference between the mean achievement scores of the experimental group and control group in the multiple choice and practical posttests in favor of the experimental group. Additionally, the students in the experimental group had significantly higher scores in the multiple choice and practical posttests in comparison to the pretest phases. Moreover, the differences between the mean achievement gain scores on multiple choice and practical pretests and posttest are significant in the favor of the experimental group. According to these experimental findings, the screencasts can be used as supplementary media to promote achievement and knowledge acquisitions of the undergraduate students in spreadsheet applications.

Keywords: Screencasts, screencasting, social networking, achievement, knowledge acquisition, spreadsheet applications, Turkish undergraduate students

\section{Introduction}

Screencasting has become a popular method of presenting content for instruction (Brown, Luterbach, \& Sugar, 2009; Lloyd \& Robertson, 2012; Winterbottom, 2007). It is a way to present digitally recorded play back of computer screen output that may contain audio narration and to visu-

Material published as part of this publication, either on-line or in print, is copyrighted by the Informing Science Institute. Permission to make digital or paper copy of part or all of these works for personal or classroom use is granted without fee provided that the copies are not made or distributed for profit or commercial advantage AND that copies 1) bear this notice in full and 2) give the full citation on the first page. It is permissible to abstract these works so long as credit is given. To copy in all other cases or to republish or to post on a server or to redistribute to lists requires specific permission and payment of a fee. Contact Publisher@InformingScience.org to request redistribution permission. ally demonstrate procedural information to students such as creating a graph in a spreadsheet program (Sugar, Brown, and Luterbach, 2010). Screencasts are defined as digital recording of a video of activities on a computer screen, and they are also known as "streaming desktop video captures" and "screen captures" (Betty, 2008; Peterson, 2007; "Screencast," 2013). In a screencast, the in- 
structor may record all screen activities (e.g., mouse clicks) to complete a designated task. The direct capture of screen activities and images continuously is a common feature of an instructional screencast (Sugar, Brown, \& Luterbach, 2010). Also, the screencasts can be accompanied with audio to create a multimedia presentation that clearly explains the actions, activities, thoughts, and supporting details of the instructor (Peterson, 2007; Sugar, Brown, \& Luterbach, 2010).

Instructional screencasts and online video tutorials have been developed to teach a wide variety of topics, including undergraduate student research (Jenkins-Brown, 2008, cited in Sugar, Brown, \& Luterbach, 2010), assistive technologies (Van Laarhoven et al., 2008), object-oriented programming (Lee, Pradhan, \& Dalgarno, 2008), mathematical modeling (Ellington \& Hardin, 2008) and nursing (Phillips \& Billings, 2007). Moreover, screencasting can be a medium for various purposes such as demonstrating algorithms for problem solving, supporting software instructions, and providing interpretation-based conceptual understanding in an active learning format (Lloyd \& Robertson, 2012). In addition, screencasting may encourage meaningful learning according to the cognitive theory of multimedia learning. Specifically, multimodal information presented as combinations of narration and animation may lead to problem-solving transfer in novel situations and may encourage active cognitive processing and cognitive load reduction to promote deeper learning (Mayer, Fennell, Farmer, \& Campbell, 2004; Mayer \& Moreno, 2003).

\section{Literature Review}

Screencasts have been used extensively in information literacy and computer science; for example, reference librarians use screencasts to show steps in how to find information in databases, searching tools, and writing citations (Betty, 2008; Carr \& Ly, 2009; Gravett \& Gill, 2010; Williams, 2010). Moreover, screencasts have been used in mathematics, material science, and engineering units. In a study conducted by Mullamphy, Higgins, Belward, and Ward (2010) screencasts were used successfully to supplement mathematics lectures. Furthermore, Wilkes (2012) conducted a study to determine if screencasts are easy to use, help students understand mathematical concepts, and are helpful for revision. The students found the screencasts easy to use and very helpful in assisting their understanding of mathematical concepts, especially for distance students.

In another study, Lloyd and Robertson (2012) assessed the effect of screencast tutorials on learning outcomes, including statistical knowledge, application, and interpretation. The participant students were randomly assigned to a control text tutorial or an experimental video tutorial group and were tasked with completing a novel statistics problem. The results indicated that screencast tutorials were effective and efficient media for enhancing student learning, particularly for higher order conceptual statistical knowledge compared to traditional instructional techniques.

According to Peplow (2010), in statistic courses some spreadsheet procedures particularly in MS Excel can be intricate and it is easy to make a misstep. As Excel proficiency is tested during examinations, the students pay close attention to the classroom demonstrations and exercises, but tend to forget once the class is over. The screencasts allow them to review and practice at leisure, and the teacher is no longer required to keep repeating the methodology.

Thus, screencasts can be used as supplementary media in the teaching of statistic courses and electronic spreadsheet applications to promote students' learning experiences since the students may find opportunities to re-watch the applications and practice what they have learned by following the screen activities (Lloyd and Robertson, 2012; Peplow, 2010). Furthermore, screencasts can be distributed online and users may watch them streamed over a network such as blogs and social networking sites (e.g., Facebook) (Brown-Sica, Sobel, \& Pan, 2009; Educause Learning Initiative, 2006; Lee et al., 2008). Moreover, students may post questions and comments 
about activities and applications in a screencast through the comment feature under the screencast shared in a social networking environment if they need to ask a question and make a comment. However, the effects of screencasting through a social-networking environment on undergraduate students' achievement and knowledge acquisitions in spreadsheet applications have not been sufficiently investigated. Hence, this study focuses on effects of screencasting through social networking on the Turkish undergraduate students' achievement in spreadsheet applications in a computer course.

\section{The Purpose of the Study}

The purpose of the study is to investigate effects of screencasting on the Turkish undergraduate students' achievement levels in the electronic spreadsheet applications in a computer course. In particular, this study explores whether there is any significant difference between mean achievement scores of the students in the experimental group who used the screencasts of the spreadsheet applications as supplementary media in a social networking environment (i.e., Facebook) and the students in the control group who did not use the screencasts. The effects of screencasts on the students' achievement are investigated according to the both paper based multiple choice test and practical or hands-on test. Specifically, this study explores the following research questions in two sections based on the type of the tests:

1. Is there a significant difference between the mean achievement scores of the students in the experimental and control groups in the multiple choice and practical pretests?

2. Is there a significant difference between the mean achievement scores of the students in the experimental and control groups in the multiple choice and practical posttests?

3. Is there a significant difference between the mean achievement scores of the experimental group depending on the multiple choice and practical pretests and posttests?

4. Is there a significant difference between the mean achievement scores of the control group depending on the multiple choice and practical pretests and posttests?

5. Is there a significant difference between the achievement gain scores of the students in the experimental group and control group depending on the multiple choice and practical pretests and posttests?

\section{Structure of the Course}

The research was conducted in a four credit Computer I course. The course was offered during the 2011-2012 Fall semester in a faculty of education at a university in Northwest Black Sea Region of Turkey. Two groups of students took the course. The students were taught basic applications in MS Word during the first four weeks, followed by basic spreadsheet applications in MS Excel for five more weeks. Moreover, the students were taught presentation techniques and applications in MS PowerPoint during the last four weeks of the course.

\section{Methodology}

In this study, a pretest-posttest experimental design with a control group (Karasar, 2005) was applied to determine the effects of screencasting on the academic achievement of students in spreadsheet applications. 


\section{The Pretest-Posttest Control Group Model}

\section{Participants}

The participants of the study were undergraduate students in the department of Turkish Language Teaching who registered for the Computer I course in 2011-2012 Fall Semester in two groups $(\mathrm{n}=41, \mathrm{n}=44)$. An experimental group consisting of 33 students ( 22 females and 11 males $)$ and a control group consisting of 33 students ( 20 females, 13 males) were set up among the students in two groups randomly and on a voluntary basis to investigate the effects of screencasting on the students' achievement in spreadsheet applications. Most participant students in both experimental and control group declared that they did not have any significant experiences in spreadsheet applications prior to this study.

\section{Research instruments}

A paper based multiple choice achievement test and a practical test, developed by the researcher, were used to assess the students' achievement in the pretests and posttests. The development procedures of the achievement tests in spreadsheet applications are explained in detail in the following sections.

\section{Development of the multiple choice achievement test}

Initially, 35 multiple choice questions were written by the researcher in order to measure the achievement of students in MS Excel spreadsheets such as formulae, functions, shortcuts, type of graphs, tables, statistical symbols, icons, menus, and buttons. The researcher benefited from MS Excel software and two textbooks (Bal, 2009; Durmuş \& Güney 2005) when writing the items of the achievement test. The items in the multiple choice test were at knowledge and comprehension levels of cognitive domain in Bloom's taxonomy (Bloom, 1956).

The achievement test in instructional technology with 35 multiple choice items with five choices was applied to a pilot group $(\mathrm{n}=52)$ at the Faculty of Education in two different programs (i.e., Computer Education and Instructional Technology, Special Education). Then, the ITEMAN software package was used to analyze difficulty levels and discrimination powers of the 35 items. The items with lower than .30 discrimination power were considered to be insufficient. Therefore, an item (item 33) out of 35 was excluded from the multiple choice test. As displayed in Table 1, the KR-20 reliability of the retaining 34 items was found to be 0.90 , the average difficulty of the items (mean P) was found to be 0.48 , and the average discrimination power of the items (mean biserial) was found to be 0.63 . As a result, it can be stated that the multiple choice test with 34 items has a high reliability score, sufficient difficulty level and discrimination power to assess students' achievement in spreadsheets.

\begin{tabular}{|c|c|c|c|c|c|c|}
\hline \multicolumn{7}{|c|}{ Table 1. Pilot test results of the achievement test } \\
\hline $\begin{array}{c}\text { Number of } \\
\text { Examines }\end{array}$ & $\begin{array}{c}\text { Number of } \\
\text { Items }\end{array}$ & Mean & SD & KR-20 & Mean P & Mean Biserial \\
\hline 52 & 34 & $16.308^{*}$ & 8.025 & 0.9 & 0.48 & 0.63 \\
\hline
\end{tabular}

\section{Development of the practical test}

The researcher developed a hands-on practical test that contained three questions, one of which consisted of six sub questions, to measure the achievement of students in spreadsheet applications 
in MS Excel. The questions in the practical test were at application level of cognitive domain in Bloom's taxonomy (Bloom, 1956). The questions were related to educational applications of spreadsheet such as calculation of an average score of a student in a course based on multiple exams (e.g., first and second midterm, final exam) and assignments, rounding the averages, calculation of the results as successful or unsuccessful for a course by using IF function, conditional formatting of the results, calculation of the highest and lowest scores of an exam, creation of graphics (e.g., column chart) based on the scores in the exam, decision making with AND Function in the IF function, and decision making with OR function in the IF function.

The researcher benefited from MS Excel software and two text-books that contain chapters in MS Excel (Bal, 2009; Durmuş \& Güney 2005) when developing the practical questions in spreadsheet applications. The researcher sought opinions of other teachers $(n=2)$ who have experiences in teaching spreadsheet applications about the validity of questions. The researcher removed one of the sub questions since it was similar to another sub question under the first question in the test by considering the suggestions of the teachers. Finally, the hands-on practical test consisted of three questions and one of them contained five sub questions. The first question consisting of five sub question was worth 50 points and the other questions were worth 25 points each.

Then, the researcher applied these questions to a pilot group in the department of Special Education $(n=10)$ who have not any significant prior experiences with spreadsheet applications. The students were not able to solve all questions although two students could solve one of the subquestions related to calculation of an average score of a student in a course. After that, the researcher applied these questions to another pilot group in the department of Computer Education and Instructional Technology $(\mathrm{n}=10)$ who have sufficient experiences with spreadsheet applications. Although one of the students was not able to solve the question in decision making with AND function with the IF function, most students $(n=9)$ in the pilot group were able to solve all questions without any problem. As a result, the solvability of the questions in the practical test by the most experienced students in MS Excel can be considered as evidence for the validity and reliability of the practical test.

\section{Procedures}

One of the groups was assigned as the experimental group and the other group was assigned as the control group randomly before the teacher started to teach spreadsheet applications. A pretest and posttest experimental design with a control group was used to find differences between the achievement levels of the students $(n=33)$ in the experimental group and the students $(n=33)$ in the control group. Both experimental and control groups were administered a multiple choice achievement test and a practical pretest before the experimental process to assess their prior knowledge in spreadsheet applications in MS Excel. After that, the teacher taught spreadsheet applications in MS Excel including the following: setting up a worksheet or spreadsheet (e.g., entering data, formula, summing numbers), saving and closing a workbook, working with worksheets (e.g., editing, selecting the portions of a worksheet), changing worksheet structure (e.g., inserting columns and rows, deleting and clearing cells, moving and copying data, adjusting column width), formulas and functions (e.g., using Excel functions, filling in a formula, fixing mistakes in formulas), charts (e.g., using the chart-wizard, changing the chart type, moving and resizing charts, changing the data being graphed), making decisions with IF functions, AND functions with IF functions, and OR functions with IF functions.

The students in both groups were expected to create these spreadsheet applications after the applications were shown by the teacher in MS Excel in the computer lab. The students in both groups were required to finish and submit these applications as homework on weekly basis. However, the students in the experimental group were provided screen captured videos or screencasts of the spreadsheet applications through a social networking environment (i.e., Facebook) after the 
applications were recorded through Camtasia Studio (www.techsmith.com) by the teacher when teaching the applications in the computer lab. The teacher created a group called "Excel" in Facebook and only the students in experimental group were subscribed to this group. The teacher posted and shared the screencasts in the Excel group. The students in the experimental group were informed that they could watch these screencasts and they could post questions and comments through the comment feature under the screencasts posted in the social networking environment when they needed to ask a question or make a comment. On the other hand, the students in the control group were not provided the screencasts and they were not able to watch these digital records of screen activities in spreadsheet applications. Finally, the multiple choice and practical pretests were administered as posttests to both groups after the experimental process.

\section{Data analyses}

The data obtained from the pretests and posttests were analyzed by the software program of Statistical Package for the Social Sciences (SPSS). The t-tests for both independent and paired sample groups were applied to answer the research questions.

\section{Results}

The results of the study are provided in two sections. The pretest and posttest results of the multiple choice test are presented in the Section 1, and the pretest and posttest results of the practical test are presented in the Section 2.

\section{Section 1}

\section{Experimental and control groups on multiple choice pretest}

An independent sample t-test was applied to determine if there was any significant difference between the mean achievement scores $(\mathrm{M})$ of the experimental $(\mathrm{N}=33)$ and control $(\mathrm{N}=33)$ groups on the multiple choice pretest at a significance level of .05 . The results showed that the difference between the mean scores of the experimental group $(\mathrm{M}=32.26, \mathrm{SD}=8.10)$ and control group $(\mathrm{M}=33.15, \mathrm{SD}=8.39)$ was not significant $(\mathrm{t}=-.439, \mathrm{df}=64, p=.662)$. Therefore, both groups can be treated as equal based on their pretest scores.

\section{Experimental and control groups on multiple choice posttest}

The independent sample t-test was conducted to detect if there was any significant difference between the mean achievement scores of the experimental and control groups on the multiple choice posttest. The results indicated that there was a significant difference at .05 level between the mean scores of the experimental group $(\mathrm{M}=73.44, \mathrm{SD}=11.59)$ and control group $(65.95=12.32)(\mathrm{t}$ $=2.542, \mathrm{df}=64, p=.013)$. Based on this finding, it can be stated that the performance of the experimental group on the multiple choice posttest was better than that of the control group.

\section{Experimental group on multiple choice pretest and posttest}

A paired samples t-test result indicated that there is a significant difference between the multiple choice pretest $(\mathrm{M}=32.26, \mathrm{SD}=8.10)$ and posttest $(\mathrm{M}=73.44, \mathrm{SD}=11.59)$ mean scores of the experimental group $(\mathrm{N}=33)(\mathrm{t}=-21.738, \mathrm{df}=32, p=.000)$. The students had notably higher scores in the posttest than in the pretest phase. Therefore, it can be stated that screen-casting on the spreadsheet applications affected the achievement of the students on the multiple choice posttest positively at the .05 significance level. 


\section{Control group on multiple choice pretest and posttest}

The paired samples t-test result revealed that there is a significant difference between the multiple choice pretest $(\mathrm{M}=33.15, \mathrm{SD}=8.39)$ and posttest $(\mathrm{M}=65.95, \mathrm{SD}=12.32)$ mean scores of the control group $(\mathrm{N}=33)(\mathrm{t}=-15.175, \mathrm{df}=32, p=.000)$. According to this result, it can be stated that teaching spreadsheet applications in the computer lab without using the screencasts has also positively affected the students' academic achievements on the multiple choice test.

\section{Experimental and control groups on achievement gain scores based on multiple choice test}

The findings in Table 2 indicates that the difference between the mean achievement gain scores on multiple choice pretest and posttest is significant in the favor of the experimental group $(\mathrm{t}=$ $2.915, \mathrm{df}=64, p=.005)$. According to this result, the mean achievement gain score of the students who benefited from the screencasts of spreadsheet applications is significantly higher than that of the students who did not use the screencasts.

\begin{tabular}{|c|c|c|c|c|c|c|c|c|c|c|}
\hline \multirow{2}{*}{ Groups } & \multicolumn{3}{|c|}{ Pretest } & \multicolumn{2}{|c|}{ Posttest } & \multicolumn{2}{|c|}{$\begin{array}{l}\text { Achievement } \\
\text { Gain Score }\end{array}$} & \multirow[b]{2}{*}{$\mathrm{df}$} & \multirow[b]{2}{*}{$\mathrm{t}$} & \multirow[b]{2}{*}{$\mathrm{p}$} \\
\hline & $\mathrm{N}$ & $\mathrm{M}$ & SD & $\mathrm{M}$ & SD & M & SD & & & \\
\hline Experimental & 33 & 32.26 & 8.10 & 73.44 & 11.59 & 41.18 & 10.88 & \multirow{2}{*}{64} & \multirow{2}{*}{2.915} & \multirow{2}{*}{$.005^{*}$} \\
\hline Control & 33 & 33.15 & 8.39 & 65.95 & 12.32 & 32.80 & 12.41 & & & \\
\hline
\end{tabular}

\section{Section 2}

\section{Experimental and control groups on practical pretest}

Seven students out of 33 in the experimental group were able to solve some of the questions in the practical test. However, the other students $(n=26)$ did not prefer to take the practical test after seeing the questions since they did not have sufficient knowledge and experience to solve the practical questions in spreadsheet applications. Similarly, only eight students out of 33 in the control group took the practical test and solved some of the questions in the practical test. On the other hand, most students $(\mathrm{n}=25)$ did not prefer to take the test because they would not able to solve the questions in the practical test. Thus, the pretest scores of students who did not take the practical test in both experimental and control group were calculated as zero (0).

An independent sample t-test was applied to determine if there was any significant difference between the mean achievement scores of the experimental and control groups on the practical pretest at a significance level of .05. The results showed that, the difference between the mean scores of the experimental group ( $\mathrm{M}=9.69, \mathrm{SD}=19.11)$ and control group $(\mathrm{M}=9.09, \mathrm{SD}=17.20)$ was observed as insignificant $(\mathrm{t}=.135, \mathrm{df}=64, p=.893)$. Thus, both groups can be treated as equal based on their practical pretest scores.

\section{Experimental and control groups on practical posttest}

The independent sample t-test results reveled that there was a significant difference at .05 level between the mean scores of the experimental group $(\mathrm{M}=78.93, \mathrm{SD}=13.56)$ and control group $(\mathrm{M}=69.24, \mathrm{SD}=17.05)(\mathrm{t}=2.556, \mathrm{df}=64, p=.013)$. According to this finding, the performance 
of the experimental group on the practical posttest of the spreadsheet applications was better than that of the control group.

\section{Experimental group on practical pretest and posttest}

A paired samples t-test result indicated that there is a significant difference at .05 level between the practical pretest $(\mathrm{M}=9.69, \mathrm{SD}=19.11)$ and posttest $(\mathrm{M}=78.93, \mathrm{SD}=13.56)$ mean scores of the experimental group $(\mathrm{t}=-22.341, \mathrm{df}=32, p=.000)$. The students had notably higher scores in the practical posttest than in the pretest phase. Thus, it can be stated that screen-casting on the spreadsheet applications affected the performances of the students on the practical posttest positively.

\section{Control group on practical pretest and posttest}

The paired samples t-test results showed that there is a significant difference at .05 level between the practical pretest $(\mathrm{M}=9.09, \mathrm{SD}=17.20)$ and posttest $(\mathrm{M}=69.24, \mathrm{SD}=17.05)$ mean scores of the control group $(\mathrm{t}=-18.369, \mathrm{df}=32, p=.000)$. According to this finding, teaching spreadsheet applications in the computer laboratory without using the screencasts has also positively affected the students' academic achievements on the practical posttest.

\section{Experimental and control groups on achievement gain scores based on practical test}

The findings in Table 3 revealed the difference between the mean achievement gain scores on the practical pretest and posttest is significant in the favor of the experimental group $(\mathrm{t}=2.023, \mathrm{df}=$ $64, p=.047$ ). Based on this finding, the performances of the students who benefited from the screencasts of spreadsheet applications are remarkably better on the practical test than that of the students who did not use the screencasts.

\begin{tabular}{|c|c|c|c|c|c|c|c|c|c|c|}
\hline \multirow[b]{2}{*}{ Groups } & \multicolumn{3}{|c|}{ Pretest } & \multicolumn{2}{|c|}{ Posttest } & \multicolumn{2}{|c|}{$\begin{array}{l}\text { Achievement } \\
\text { Gain Score }\end{array}$} & \multirow[b]{2}{*}{ df } & \multirow[b]{2}{*}{$\mathbf{t}$} & \multirow[b]{2}{*}{$\mathbf{P}$} \\
\hline & $\mathbf{N}$ & M & SD & M & SD & $\mathbf{M}$ & SD & & & \\
\hline Experimental & 33 & 9.69 & 19.11 & 78.93 & 13.56 & 69.24 & 17.68 & \multirow{2}{*}{64} & \multirow{2}{*}{2.023} & \multirow{2}{*}{$.047^{*}$} \\
\hline Control & 33 & 9.09 & 17.20 & 69.24 & 17.05 & 60.15 & 18.81 & & & \\
\hline
\end{tabular}

Moreover, there existed more variance in the practical test scores than in the multiple choice scores, as displayed in Tables 2 and 3. The greater variance in the practical test scores can be explained by the remarkably lower practical pretest scores of the students than their practical posttest scores, and higher amount of hands-on or practical homework done by the students than that of theoretical or reading homework. The hands-on or practical experiences of most students in spreadsheet applications increased notably when they work on their homework. As a result, the students benefited from these experiences in the practical posttest and thereby they obtained remarkably higher scores in the practical posttest than the pretest.

\section{Discussion}

The purpose of the study is to investigate effects of screencasting on the Turkish undergraduate students' achievement levels in the electronic spreadsheet applications in a computer course. 
There was no significant difference between the mean scores of the experimental group and control group on the multiple choice pretest. However, the independent t-test results indicated that the mean score of the experimental group was significantly higher than that of the control group on the multiple choice posttest. This finding reveals that the performance of the experimental group on the multiple choice posttest was better than that of the control group. Moreover, the items in the multiple choice test were at knowledge and comprehension levels of cognitive domain in Bloom's taxonomy. Hence, it can be stated that the screencasting affected the performances and achievement of the students in knowledge and comprehension levels of cognitive domain positively. In addition, these findings are consistent with the findings of a prior studies which (Lloyd \& Robertson, 2012) indicated that screencast tutorials are an effective and efficient tool for enhancing student learning and especially for higher order conceptual statistical knowledge compared to traditional instructional techniques. Furthermore, as in line with the findings of a prior study (Wilkes, 2012), the findings of the current study reveal that screencast tutorials are helpful for the students in assisting understanding of spreadsheet concepts.

The students in the experimental group obtained significantly higher mean scores in the posttest than in the pretest phase of the multiple choice test. Additionally, the students in the control group had significantly higher mean scores in the posttest than in the pretest phase of the multiple choice test as well. This result reveal that teaching spreadsheet applications without using the screencast tutorials had also positive effects over the students' academic achievements on the multiple choice test. However, the mean achievement gain score of the students in the experimental group was significantly higher than that of the students in the control group on multiple choice test. Thus, similar to the findings prior studies (Basturk, 2005; Lloyd \& Robertson, 2012), this current study reveals that teaching spreadsheet applications by using screencast tutorials is more effective than the traditional way of teaching without use of the screencasts.

In addition, screencasting on the issues of spreadsheet applications affected the performances of the students in the experimental group notably in a positive direction since they demonstrated significantly higher achievement levels on the practical posttest than the students in the control group. Additionally, the posttest mean score of the students in the experimental group was significantly higher than their practical pretest mean score. Furthermore, teaching spreadsheet applications without using the screencasts has also positively affected the students' academic achievements on the practical posttest. However, the mean achievement gain scores of the students in the experimental group on the practical tests were significantly higher than that of the students in the control group who did not use the screencast tutorials. According to this finding, the academic performances of the students in the experimental group who benefited from the screencasts of spreadsheet applications were notably better than those of the students in the control group. Therefore, it can be stated that screencasting affected the performances and achievement of the students at application level of cognitive domain at Bloom's taxonomy positively. Furthermore, as consistent with findings of Lloyd and Robertson (2012) the findings of this study demonstrate that screencast tutorials are an effective tool for enhancing practical student learning in spreadsheet applications compared to traditional methods of teaching.

\section{Practical Implications}

The overall pattern of the findings of this study implies that screencasting in spreadsheet applications can be an effective method to improve performances and achievement of the students in knowledge, comprehension, and applications levels of the cognitive domain. Thus, the students may find opportunities to acquire not only theoretical and conceptual knowledge, but also practical hands-on skills in spreadsheets through the concrete illustrations in screencasts. 


\section{Conclusion and Future Study}

As a result, the findings of this study and the related literature (e.g., Lloyd \& Robertson, 2012; Peplow, 2010) suggest that the screencasts can be considered as useful supplementary media to facilitate and promote students' learning and knowledge acquisition in spreadsheet applications. Moreover, screencasting through a social networking environment can be an efficient and effective method to improve the performances of the students in spreadsheet applications. However, this study has not focused on the experiences and interactions of the teachers and students in the social networking environment and their opinions about screencasting. Hence, future studies may focus on the experiences of teachers, students, interactions in the social networking environment, and their opinions about screencasting in building an online teaching and learning community to have interactions outside classroom about spreadsheet or statistical applications.

\section{References}

Bal, H. Ç. (2009). Bilgisayar ve Internet kullanımı laboratuvar uygulamaları [Laboratory applications of computer and Internet use] (17. Bask1). Trabzon, Turkey: Murathan Yayinevi [in Turkish].

Basturk, R. (2005). The effectiveness of computer-assisted instruction in teaching introductory statistics. Educational Teaching \& Society, 8, 170-178.

Betty, P. (2008). Creation, management, and assessment of library screencasts: The Regis Libraries animated tutorials project. Journal of Library Administration, 48(3/4), 295-315.

Bloom, B. S. (1956). Taxonomy of educational objectives, Handbook I: The cognitive domain. New York: David McKay Co.

Brown, A., Luterbach, K., \& Sugar, W. (2009). The current state of screencast technology and what is known about its instructional effectiveness. In I. Gibson et al. (Eds.), Proceedings of Society for Information Technology \& Teacher Education International Conference (pp. 1748-1753). Chesapeake, VA: AACE.

Brown-Sica, M., Sobel, K., \& Pan, D. (2009). Learning for all: Teaching students, faculty, and staff with screencasting. Public Services Quarterly, 5(2), 81-97.

Carr, A., \& Ly, P. (2009). More than words: Screencasting as a reference tool. Services Review, 37(4), 408420.

Durmuş, S., \& Güney, N. (2005). Bilgisayar Kullanımı [Computer use] . Bolu, Turkey: Yonca Kitapevi [in Turkish]

Educause Learning Initiative. (2006). 7 Things you should know about screencasting. Retrieved September 11, 2012, http://net.educause.edu/ir/library/pdf/ELI7012.pdf

Ellington, A. J., \& Hardin, J. R. (2008). The use of video tutorials in a mathematical modeling course. Mathematics and Computer Education, 42(2), 109-117.

Gravett, K., \& Gill, C. (2010). Using online video to promote database searching skills: The creation of a virtual tutorial for health and social care students. Journal of Information Literacy, 4(10), 66-71.

Jenkins-Brown, A.R. (2008). Casting a wider net: Using screencast tutorials to advance library involvement in supporting research practices. Presented at the Joint Meeting of The Geological Society of America, Soil Science Society of America, American Society of Agronomy, Crop Science Society of America, Gulf Coast Association of Geological Societies with the Gulf Coast Section of SEPM. Houston, TX.

Karasar, N. (2005). Bilimsel arastırma yöntemi [Scientific research method]. (15th ed.). Ankara, Turkey: Nobel Yayın Dağıtım.[ in Turkish] 
Lee, M. J. W., Pradhan, S., \& Dalgarno, B. (2008). The effectiveness of screencasts and cognitive tools as scaffolding for novice object-oriented programmers. Journal of Information Technology Education, 7 , 61-80. Retrieved March 11, 2013, from http://jite.org/documents/Vol7/JITEv7p061-080Lee332.pdf

Lloyd, S. A., \& Robertson, C. L. (2012). Screencast tutorials enhance student learning of statistics. Teaching of Psychology, 39(1), 67-71. Retrieved March 11, 2013, from http://top.sagepub.com/content/39/1/67.full.pdf + html

Mayer, R. E., Fennell, S., Farmer, L., \& Campbell, J. (2004). A personalization effect in multimedia learning: Students learn better when words are in conversational style rather than formal style. Journal of Educational Psychology, 96, 389-395.

Mayer, R. E., \& Moreno, R. (2003). Nine ways to reduce cognitive load in multimedia learning. Educational Psychologist, 38(1), 43-52.

Mullamphy, D., Higgins, P., Belward, S., \& Ward, L. (2010). To screencast or not to screencast. ANZIAM Journal North America, 51, C446-C460.

Peplow, S. (2010). Teaching outside the textbook: A multimedia approach to teaching statistics tutorials. Transformative Dialogues: Teaching \& Learning Journal, 3(3) 1-4. Retrieved February 18, 2013, from http://kwantlen.ca/TD/TD.3.3/TD.3.3_Peplow_Teaching_outside the_Textbook.pdf

Peterson, E. (2007). Incorporating screencasts in online teaching. International Review of Research in Open and Distance Learning, 8(3). Retrieved August 10, 2012, from http://www.irrodl.org/index.php/irrodl/article/view/495/935

Phillips, J. M., \& Billings, D. M. (2007). Using webcasts for continuing education in nursing. Journal of Continuing Education in Nursing, 38(4), 152-153.

Screencast. (2013). In Wikipedia. Retrieved February 20, 2013, from http://en.wikipedia.org/wiki/Screencast

Sugar, W., Brown, A., \& Luterbach, K. (2010). Examining the anatomy of a screencast: Uncovering common elements and instructional strategies. International Review of Research in Open and Distance Learning, 11(3), 1-20. Retrieved February 20, 2013, from http://www.irrodl.org/index.php/irrodl/article/view/851/1596

Van Laarhoven, T., Munk, D. D., Zurita, L. M., Lynch, K., Zurita, B., Smith, T., \& Chandler, L. (2008). The effectiveness of video tutorials for teaching preservice educators to use assistive technologies. Journal of Special Education Technology, 23(4), 31-45.

Wilkes, J. (2012). Screencasts - Are they the panacea for dealing with students' diverse mathematical skills? Proceedings of the 2012 AAEE Conference, Melbourne, Victoria, Australia. Retrieved February 15, 2013, from http://www.aaee.com.au/conferences/2012/documents/abstracts/aaee2012-submission$\underline{84 . p d f}$

Williams, S. (2010). New tools for online information literacy. The Reference Librarian, 51(2), 148-162.

Winterbottom, S. (2007). Virtual lecturing: Delivering lectures using screencasting and podcasting technology. Planet, 18. Retrieved June, 20, 2012, from http://www.gees.ac.uk/planet/p18/sw.pdf 


\section{Biography}

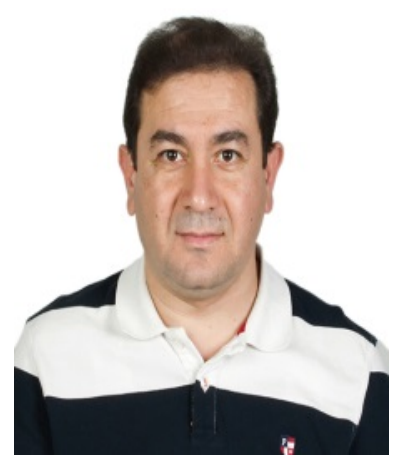

Erkan Tekinarslan holds a Ph.D in Instructional Technology from Ohio University, Athens, Ohio, U.S.A. He is an Associate Professor in the Department of Computer Education and Instructional Technology, Faculty of Education, Abant Izzet Baysal University, Bolu, Turkey. His areas of research interest include uses of Information and Communication Technologies (ICTs) in Education, uses of social media in education, e-learning and blended learning. His research has been published in various journals including Australasian Journal of Educational Technology, The International Review of Research in Open and Distance Learning, and Computers in Human Behavior. 